\title{
O MICROPODER NO PROCESSO DE TRABALHO DENTRO DA ESTRUTURA HOSPITALAR: VIVENCIANDO UMA HISTÓRIA
}

MICROPOWER IN THE WORK PROCESS IN HOSPITAL STRUCTURE: LIVING A HISTORY

Elisabeta Albertina Nietsche ${ }^{1}$

RESUMO: Este artigo procura retratar, através de uma história, as relações de micropoderes que perpassam pelo processo de trabalho de alguns profissionais dentro dos serviços de um hospital. A base teórica que sustenta a interpretação da história está nos estudos de Foucault e autores que interpretam seus escritos. São trabalhados os seguintes micropoderes: da Instituição-Estrutura Hospitalar, da Informação e sobre o Corpo.

UNITERMOS: Poder - Micropoder - Estrutura hospitalar - Ética.

\section{APRESENTAÇÃO}

$\mathrm{Na}$ tentativa de buscar um tema para ser apresentado no $47^{\circ}$ Congresso Brasileiro de Enfermagem, despertou-me interesse desenvolver algumas questões acerca de micropoderes que ocorrem dentro da estrutura hospitalar. Este trabalho procura retratar, através de uma história, as relações de micropoderes que perpassam dentro do serviço de um hospital.

Cabe ressaltar que não pretendo esgotar o assunto, mas provocar um momento de reflexão sobre essa temática tão importante e que está presente no dia a dia de nossa vida pessoal e profissional.

Para um melhor entendimento dos micropoderes manifestados na história que conto e interpreto a seguir, gostaria de escrever algumas concepções que Foucault apresenta sobre o poder. Para tanto utilizei suas obras "Microfísica do Poder", "Vigiar e Punir" e citações de autores que interpretaram seus escritos, como Deleuze (1995), Machado (1993), Morey (1990), esses dois últimos estão incluidos em seus livros, "Microfísica do Poder" e "Un diálogo sobre el poder y otras conversaciones, e Lunardi (1994).

\footnotetext{
${ }^{1}$ Enfermeira. Professora Assistente do Departamento de Enfermagem da Universidade Federal de Santa Maria. Membro do GEPES - UFSM e Doutorandà da UFSC.
} 
Portanto, pontuarei de forma global essas concepções.

\section{Para Foucault.}

- o poder é uma relação de forças, ou melhor, toda relação de força é uma "relação de poder";

- os poderes se exercem em níveis variados, em pontos diferentes da rede social e neste complexo os micropoderes existem integrados ou não ao Estado;

- micropoder é a mecânica de poder que se expande por toda a sociedade, assumindo as formas mais regionais e concretas, investindo em instituições; tomando corpo em técnicas de dominação. Poder esse que intervém materialmente, atingindo a realidade mais concreta dos indivíduos - o seu corpo - e que se situa ao nivel do próprio corpo social, e não acima dele, penetrando na vida cotidiana e por isso caracterizado como micropoder ou subpoder.

Foucault procurou, em seus trabalhos, tratar deste nivel molecular de exercício de poder sem partir do centro - Estado como órgão único de poder, mas para a periferia - estrutura social onde são produzidos os mecanismos e técnicas infinitesimais de poder que estão intimamente relacionadas com a produção de determinados saberes. Estudou o poder não como uma dominação global e centralizada que se pluraliza, se difunde e repercute nos outros setores da vida social de modo homogêneo, mas como tendo uma existência própria e formas especificas ao nivel mais elementar;

- os poderes não estão localizados em nenhum ponto específico da estrutura social. Funcionam como uma rede de dispositivos ou mecanismos a que nada ou ninguém escapa, a que não existe exterior possivel, limites ou fronteiras;

- o poder deve ser analisado como algo que circula, que só funciona em cadeia. Nunca está localizado aqui ou alí, nunca está nas mãos de alguns, nunca é apropriado como uma riqueza ou um bem;

- o poder não é propriedade de ninguém. É algo que se exerce, que se efetua, que funciona como uma maquinaria, como uma máquina social que não está situada em um lugar privilegiado ou exclusivo, mas se dissemina por toda a estrutura social. Não é um objeto, uma coisa, mas uma relação;

- as relações de poder não se passam fundamentalmente nem ao nível do direito, nem unicamente repressivas. $O$ poder não é essencialmente repressivo (já que "incita, suscita, produz"); ele se exerce antes de se possuir (já que só possui sob uma forma determinável - classe - e determinada - Estado); passa pelos dominados tanto quanto pelos dominantes (já que passa por todas as forças de relação);

- o poder não age necessariamente por violência, repressão e ideologia. Foucault, diante de uma imagem negativa do poder, que proíbe, oculta, 
sufoca e nega, mostra toda a sua positividade: o poder produz, produz verdade, produz saber e "produz o real através de uma transformação técnica dos indivíduos, que em nossa sociedade recebe um nome: normalização" (Morey apud Foucault, 1990: 5);

- onde há poder há resistência ou possibilidade de resistência;

- todo saber assegura o exercício de poder;

- o poder é produtor de individualidade. $O$ indivíduo é uma produção do poder e do saber;

- não há relação de poder sem constituição de um campo de saber, como também reciprocamente todo saber constitui novas relações de poder.

Um tipo específico de poder que Foucault (1993: 153) aborda em seus estudos é o "poder disciplinar" , e para ele esse poder é:

\footnotetext{
1... com efeito um poder que, em vez de se apropriar e de vetirar, tem como funcião "adestrar"; ou sem divida adestrar para retivar e se apropriar ainda mais e melhor. Ele nâo amarra as forghas para reduzi-las, procura ligá-las para multiplica-las e utilizá-las num todo. (...) a disciplina fabrica individuas, ela é a técnica especifica de um poder que toma os individuos as mesmo tempo como objetos como instrumentos de seu exercicio.
}

Cabe ainda ressaltar que o poder disciplinar não é uma instituição, um aparelho, pois funciona como uma rede que as atravessa sem limitar suas fronteiras.

Machado (1993; 17 e 18) resume em quatro características básicas do poder disciplinador enfocados por Foucault. Essas características são interrelacionadas e discutidas a seguir:

1) A disciplina é um tipo de organização do espaço. É uma distribuição dos indivíduos através da inserçã̃o dos corpos em um espaço individualizado, classificatório, combinatório. Essa não é uma característica importante porque as relações de poder disciplinar não necessitam necessariamente de espaço fechado;

2) A disciplina é um controle do tempo, estabelece uma sujeição do corpo ao tempo, com o objetivo de produzir o máximo de rapidez e o máximo de eficácia.

3) A vigilância é um de seus principais instrumentos de controle. Deve ser contínua, perpétua, permanente; que não tenha limites, permite nos lugares mais recônditos, esteja presente em toda a extensão do espaço.

4) A disciplina implica um registro contínuo de conhecimento. Ao mesmo tempo que exerce um poder, produz um saber. 
Após essas colocações e com esse olhar, gostaria de convidá-lo a transformar-se em uma "borboleta", para conhecer a estrutura de um hospital e possibilitar desta forma que você possa captar melhor as relações de micropoderes expressas na história a seguir descrita.

\section{CONTANDO A HISTÓRIA}

Dona Curiosidade é uma "borboleta" esperta, investigadora, perspicaz e curiosa. Certo dia, voando pelas ruas da cidade, começou a observar o movimento dos carros, o colorido da natureza, o corre-corre das pessoas, a rotina do trabalho, o relacionamento dos seres humanos, a estrutura e a organização dos serviços prestados à população... De repente, deparou-se com um prédio enorme chamado "HOSPITAL" e, na porta de entrada, havia uma multidão...

Dona Curiosidade ficou perplexa com o "tamanho da estrutura" e porque tantas pessoas entravam e saíam do mesmo, demonstrando em suas fisionomias um grau de insatisfação, de revolta, de tristeza.. Tudo isso e muito mais despertou o interesse de Dona Curiosidade para entrar e conhecer este "Gigante Hospital". Ficou em dúvida de como entrar, por onde entrar. Teve uma idéia! Voou e pousou no boné do guarda que controlava a entrada das pessoas e, com isso, possibilitou seu ingresso no recinto de marcação de consultas de forma mais rápida. Era tanta a confusão que resolveu observar esse local com os olhos bem atentos e com uma caderneta para anotar os seus registros.

Neste momento, Maria, uma senhora de 65 anos que aguardava há quatro horas na fila para marcar uma consulta com o neurologista, chegou ao guichê $n^{\circ}$ 3 com sua carteirinha e diz:

- Moço, quero marcar uma consulta com o neurologista.

- Não é neste guichê. Procure o guichê $n^{\circ} 6$.

Chegando no guichê $n^{\circ} 6$, Maria se manifesta:

- Moça, o moço do guichê ali do lado, disse para eu vir aqui marcar uma consulta com o neurologista.

- Sinto muito, minha senhora, o guichê onde marcam a consulta para o neurologista mudou na semana passada e agora fica no corredor à esquerda.

Maria cansada, desorientada, apavorada e sentido-se uma "bolinha de pingue-pongue", conseguiu, enfim, chegar ao guichê, onde falou:

- Moço, a moça do outro lado do corredor disse que aqui se marcava consulta para o neurologista. 
- Sim, é aqui, mas as consultas já foram todas marcadas. A senhora terá que voltar nos dias 4 e 5 do próximo mês e, se quiser realmente uma vaga, venha no dia anterior e durma na fila.

- Mas, moço, eu sou uma pessoa de idade, muito doente, aposentada, moro longe daqui. Para "pegar" o ônibus, preciso caminhar $3 \mathrm{~km}$ até a estrada. Não tem como falar com o médico para ver se ele me atende?

- As informações que eu tinha para the oferecer já foram dadas. Tenho ordens expressas do médico neurologista; ele não atende mais que cinco pessoas no seu horário para não atrasar 0 atendimento em seu consultório particular. Minha senhora, estamos cumprindo nosso papel e as normas do hospital. Bom dia, até o mês que vem. O próximo por favor...

- Mas moço!?!??

Maria saiu chorando, decepcionada, não sabendo o que fazer...

Dona Curiosidade, espantada com o fato, começou a interrogar-se: como uma pessoa que paga altos impostos e ao precisar de serviços de saúde não é atendida? como as normas são estabelecidas dentro da estrutura hospitalar? a quem o hospital atende? por que o médico estabelece seu número de consultas? por que os funcionários são tão "disciplinados"?

Dona Curiosidade fez suas anotações e resolveu voar e conhecer outro setor. Pousou no suporte de solução da sala de atendimento do Pronto-Socorro e atentou para os fatos que estavam ocorrendo.

Num banco grande e sem conforto encontravam-se várias pessoas aguardando para serem atendidas: um com braço fraturado, outro em crise convulsiva, outra com ameaça de aborto, outro com enxaqueca violenta,...

De repente, uma mãe aos gritos e prantos entra no pronto-socorro com seu filho nos braços e coloca-o na maca. A enfermeira Denise se aproxima e diz:

- Mãe, aguarde lá fora, aqui não é o seu lugar no momento.

A mãe se retirou e a porta da sala foi fechada.

O menino de oito anos, que sofrera uma fratura no fêmur, chorava de dor e pedia pela mãe. O médico de plantão, Ricardo, aproximou-se do garoto e com a ajuda da auxiliar de enfermagem Cláudia, despiu o menino, examinou-o e o interrogou:

- Dói aqui? E aqui?

- Dóóóói. Sai daí, quero minha mãe.

- Como foi que aconteceu o acidente?

- Não me lembro, só sei que foi um carro que me atropelou... Por favor, quero minha mãe. Me tape, estou com frio.

O médico continuou examinando e não deu muita atenção ao que o menino expressava. Ricardo chama a enfermeira: 
- Denise, prepara duas ampolas de Dorscopena em $500 \mathrm{ml}$ de solução fisiológica. Instale à 20 gotas por minuto. Volto logo, vou chamar meus alunos e o médico especialista. Achei essa fratura interessante, quero que eles vejam.

$O$ médico se retirou. A enfermeira junto com a auxiliar instalaram a solução fisiológica, verificaram os sinais vitais e cobriram o menino.

Passaram-se duas horas. A mãe angustiada e sem informações sobre 0 estado de saúde do filho, bate na porta, abre e:

- Psiu! Psiu!... Enfermeira, por favor, como está o meu filho? Afinal, o que atingiu no seu corpo?

- Ó mãe, não the disse para aguardar lá fora? Ainda não é o momento de ficar aqui.

A mãe aflita novamente se retira e senta no banco esperando que alguém traga notícias de seu filho.

Enquanto isso, o menino pergunta à enfermeira:

- Hei, moça de branco, era minha mãe que estava falando contigo?

- Não. Fique quietinho, para não doer mais. O médico já estará de volta.

- Tia, estou com sede e quero água. Chame minha mãe que ela me dá água.

O médico estava demorando para voltar e a enfermeira não sabendo se o menino iria ou não realizar cirurgia resolveu, mesmo assim, oferecer um pouco de água.

Dona Curiosidade estava inquieta observando os acontecimentos e anotando todos os detalhes.

Passaram-se 4 horas... A mãe volta a bater na porta e pergunta:

- Enfermeira, como está meu filho?

- Quem pode dar esta informação é o médico. Ele não está aqui. Foi chamar um especialista. Mas não se preocupe, o caso vai ser resolvido com ou sem cirurgia.

- O quê?

- Nada não, depois the daremos maiores informações. A senhora já preencheu a fichinha com a secretária?

- Não. favor.

- Vá preenchê-la, é importante para registrarmos o fato. Aguarde lá fora por

A mãe se retirou mais uma vez...

O médico retornou junto com seus alunos e o especialista em traumatologia e se aproximaram do menino. examinar.

- E ai garoto, tudo bem? Olha, trouxe um "grande" especialista para te 
- Não, estou com dor e sede. Não quero que me examinem, quero minha mãe.

Interrompe a enfermeira:

- Doutor, a mãe do garoto está aguardando pelas informações sobre o estado dele. Ah, dei um pouco de água para ele beber.

- O quê? Quem te autorizou a fazer isso? Quantas vezes precisamos falar que somos responsáveis pelos pacientes. Os pacientes são nossos.

Dona Curiosidade balança a cabeça...

A enfermeira responde rapidamente:

- Sim doutor, mas nós também somos responsáveis. Devemos trabalhar juntos.

O médico deu um sorriso e continuou falando...

- Ah! Ah! Vejam como essa fratura é interessante. O fêmur acavalou-se e desviou-se à esquerda comprometendo grande massa muscular...

O médico plantonista, o especialista e os alunos examinaram por mais meia hora a "fratura interessante" do menino e chegaram à seguinte conclusão: que sua redução somente era possivel através de cirurgia. Resolveram chamar a mãe.

- Denise, pede para a mãe do garoto entrar.

A mãe triste, apavorada e ansiosa aproximou-se do filho, beijou-o e disse:

- Paulinho, meu filho querido, como estás?

- Agora estou bem mãe. Você está aqui.

- Mãe, chamamos você aqui para lhe dizer que seu filho sofreu uma fratura muito séria e que teremos de submetê-lo à cirurgia.

- O quê? Isso não é muito perigoso?

- Não, ele é um garoto e vai reagir bem.

Paulinho foi para a cirurgia e...

Dona Curiosidade apavorada questiona-se: Por que é tão difícil ter acesso às informações? Por que o médico sabe tudo e quer mandar em todos? Por que ninguém se preocupou em saber o nome do menino e considerá-lo como um ser humano? A "fratura interessante" é tão importante assim? Por que a mãe precisou ficar angustiada por tanto tempo? Será que encontrariamos um prontosocorro diferente? Onde será? Não quero mais ficar aqui, vou voar para o sexto andar e conhecer a Unidade de Internação e Clínica Médica.

Chegando lá, Dona Curiosidade pousou no posto de enfermagem e procurou entender quem era quem e o que se fazia neste setor.

Neste momento, a Tânia, auxiliar de enfermagem, e a Dalva, técnica de enfermagem, preparavam a medicação e aproveitavam para conversar sobre os 
baixos salários, o sofrimento delas frente ao estado de saúde dos pacientes, falta de material mínimo para realizarem suas atividades, colocando muitas vezes suas próprias vidas em risco.

Neste instante, entra a Vanusa, enfermeira-chefe, e pergunta:

- Que conversa é essa?

- Olha chefe, estávamos conversando sobre nós trabalhadores.

- Ora, isso não é hora para tratar deste assunto. Vamos mais rápido com esse preparo de medicação, pois os leitos 5 e o 23 terão que descer para o RX Os leitos 4 e 7 precisam ser higienizados antes que 0 Dr. Cássio chegue. Preciso rever todas as prescrições médicas para verificar se tudo foi realizado e checado. Estou atrasadíssima. Ah... ainda preciso falar com a nutricionista para resolver o problema da dieta do leito 15 e com o fisioterapeuta para avaliar o leito 8.

- Chefe, você corre-corre todo o dia para arrumar a "casa dos outros". Gostaria que parasse um pouco para nos ouvir.

- Vou procurar um tempo, prometo. Agora não posso. Ah... não esqueçam de trocar os curativos e encaminhar os pedidos de exame que os médicos solicitaram.

Dona Curiosidade registra tudo em sua caderneta.

Passam-se algumas horas e chega o Dr. Cássio com seu avental branco, estetoscópio pendurado no pescoço e com uma pose de "dono do saber". Dirigese ao pessoal de enfermagem e...

- Bom dia meninas. Como está meu paciente?

- Está triste, não quer comer, falar. Acho que está assim porque não sabe seu diagnóstico.

- Vou vê-lo. Tânia arruma o material de punção lombar, precisarei dentro de 15 minutos.

- Sim, vou providenciar o mesmo.

O médico dirige-se ao leito do paciente. Dona Curiosidade sempre alerta resolveu acompanhá-lo até a enfermaria e...

- Bom dia, rapaz. Como tens passado?

- Bom dia. Tenho passado mais ou menos. Estou querendo saber o que eu tenho. Ando muito angustiado.

- Mas o que é isso, não se preocupe. Preciso fazer mais exames e aqui você está bem cuidado.

- Tenho äinda dúvidas, doutor. Não aguento mais. Falo e parece que ninguém me ouve, até o senhor. Não sei porque me manipulam tanto, como se eu fosse um objeto. Vem um, vem outro e assim por diante. 
- Mas moço, você está num "hospital", portanto precisa se submeter a tudo isso e dar "graças a Deus" de que está sendo atendido.

- Concordo em parte com o que o senhor está dizendo, mas perder a identidade... é difícil de aceitar. Afinal doutor, o que eu tenho?

- Não seja tão curioso. Aguarde.

- É, estou cansado de esperar. Já perguntei para várias pessoas sobre o meu estado de saúde. Todos me "enrolam" e dizem para eu perguntar ao senhor.

- Ah! ah! ah!... Ansiedade não faz bem a ninguém, descanse. Vou prescrever mais dois remédios e solicitar três exames para amanhã. Ok! Tchau! Volto à tarde.

O paciente ficou indignado, pois continuava sem resposta para a dúvida sobre seu estado de saúde.

Dona Curiosidade suspirou e... voou, quando, de repente, deparou-se com a auxiliar de enfermagem Tânia e a enfermeira Vanusa.

- Enfermeira Vanusa, o familiar do leito 3 ainda está aí. Já falei que o horário de visitas acabou e ele precisa retirar-se. Esses familiares... o que incomodam.

- Deixa comigo, já vou resolver isso.

A enfermeira aproximou-se do leito 3 e com uma voz de autoridade falou ao familiar:

- Terminou seu horário e, se você não for embora, não autorizo mais sua entrada quando solicitar. Caso você não saia, chamarei o guarda.

Nesse instante o paciente começa a chorar e fala à enfermeira:

- Sniff... sniff... enfermeira, por favor, deixe minha mãe ficar, estou angustiado, sniff...

- Não posso. As normas foram feitas para serem cumpridas. Abrir uma exceção é correr riscos... Até logo, e não esqueça, só uns minutinhos, senão chamo o guarda.

A enfermeira retirou-se. A mãe despediu-se do filho e saiu com medo de que fizessem alguma "coisa" com ela e com o filho.

Dona Curiosidade apontou todos os detalhes: hierarquia do serviço de enfermagem, subordinação do auxiliar e técnico à enfermeira e esta ao médico, falta de trabalho em equipe, uso inadequado da autoridade (enfermeira, médico), falta de condições adequadas para o trabalho, necessidade de espaço para conversar, mais preocupação com a execução da técnica do que com o ser humano, não respeito às dúvidas e identidade do paciente...

Depois desses apontamentos, resolveu procurar um setor que fosse diferente, mais ameno. Voou e desceu para a ala administrativa do hospital. Encontrou uma sala com a porta entreaberta, entrou e pousou. Adivinha de quem era essa sala? Era do Diretor-Geral e estava acontecendo uma reunião 
executiva com as Direções Clínicas, de Enfermagem, de Ensino e Pesquisa e Administrativa.

Dona Curiosidade, muito esperta, resolveu ficar para ouvir sobre o que estavam tratando. Naquele momento, olhou atentamente para a parede e avistou um quadro com os seguintes dizeres:

\section{FILOSOFIA DO HOSPITAL}

Este estabelecimento de saúde tem por primeiro objetivo atender de forma integral o SER HUMANO em suas necessidades independente de credo, raça, idade, sexo... procurando promover e restabelecer sua saúde. Para que isso ocorra, todos os profissionais devem estar comprometidos ...

A Direção

Após ler o mesmo, anotou em sua caderneta...

O Diretor Geral abre a sessão. Faz a leitura da ata e coloca a pauta da reunião: "Vamos tratar sobre redução de custos". Após muitas discussões, os membros deliberam o seguinte: demissão de funcionários, redução de número de leitos, comprar material estritamente necessário e mais barato, as rotinas de enfermagem devem ser revistas para diminuir os gastos...

Dona Curiosidade, espantada, triste, confusa, não agüentou mais a sufocação. Voou e saiu do recinto hospitalar em direção ao galho de uma árvore, onde posou. Desse lugar avistava o "Gigante Hospital" e questionava-se: que estrutura é essa? É possivel construir outra diferente? Acho que não tive sorte em escolher esse dia para conhecer este "Magnífico Prédio". Talvez os outros dias não sejam assim, sejam melhores...

Dona Curiosidade fechou sua caderneta de anotações e encerrou-a com as seguintes palavras:

"AINDA BEM QUE BORBOLETA NĀO PRECISA DE HOSPITAL"

\section{INTERPRETANDO A HISTÓRIA}

A história que acabamos de ler, por si só, fala mais alto do que qualquer interpretação, pois cada "borboleta" em que você se transformou, com seu olhar diferente, pode captar várias mensagens que auxiliará na reflexão sobre as questões de micropoderes dentro de uma estrutura hospitalar.

Tentarei pontuar alguns micropoderes que perpassam pela história, deixando que $o$ interesse, a curiosidade e a imaginação de cada um complete minha interpretação que se baseia nas contribuições, principalmente de Foucault.

A seguir, passo a enumerar e comentar os micropoderes. 


\section{MICROPODER DA INSTITUIÇÃO/ ESTRUTURA HOSPITALAR}

Para entender esse micropoder passo a historiar o nascimento do hospital enquanto instrumento terapêutico.

O hospital, até o final do século XVIII, era um local de separação / exclusão, onde se prestava assistência aos pobres que estavam morrendo. Portanto, o hospital era considerado um morredouro. O profissional médico não fazia parte desta instituição. A experiência hospitalar estava excluída da formação ritual do médico; o que o qualificava era a transmissão de receitas e não o campo de experiências que ele teria atravessado, assimilado e integrado.

A intervenção do médico na doença era organizada através da noção de crise, através da qual o médico observava o doente e a doença para detectar seus primeiros sinais e descobrir o momento em que a crise apareceria, isto é, o momento em que se afrontavam, no doente, a natureza sadia do indivíduo e o mal que 0 atacava.

Portanto, nada da prática médica permitia a organização do hospital e nada da organização do hospital permitia a intervenção da medicina.

O pessoal hospitalar era constituído por religiosos e leigos que prestavam assistência e praticavam caridade como forma de garantir a salvação eterna.

Essa configuração/organização do hospital começa a mudar a partir do final do século XVIII, buscando uma anulação dos efeitos negativos do hospital, purificando-o dos efeitos nocivos, da desordem que ele acarreta, ou seja, das doenças que ele podia suscitar nas pessoas internadas e espalhar na cidade em que estava situado, como também a desordem econômico-social de que ele era foco perpétuo.

A partir dessa época, o hospital é concebido como um instrumento terapêutico, onde o médico começa a intervir. Ocorre a disciplinarização do espaço hospitalar e a transformação do saber e da prática médica. O hospital é um meio de intervenção no doente e o médico passa a ser o principal responsável pela organização hospitalar.

A tomada do poder médico se manifesta no ritual da visita ao leito do doente, onde ele vai à frente, e após os assistentes, alunos, enfermeiros, etc. Esse advento do poder médico é encontrado nos regulamentos dos hospitais no século XVIII.

O hospital, além de um local de cura, ainda transformou-se em um campo documental de registro, acúmulo e formação do saber. O saber médico começa a ter seu lugar, no que é cotidianamente registrado na tradição viva, ativa e atual que é o hospital. A clínica aparece como uma dimensão essencial do hospital, aqui entendida como a organização do hospital sendo um lugar de formação e transmissão do saber.

Essa reorganização decorreu de uma tecnologia política chamada por Foucault (1993) de disciplina: que é uma técnica de exercício de poder que 
permite esquadrinhar, contratar, vigiar, classificar, distribuir, gerenciar tanto os doentes hospitalizados como quem os cuida. Busca o controle sobre os seres humanos, seu espaço, seu trabalho, de modo a aumentar sua capacidade de produção e a tornar-se útil.

No espaço hospitalar disciplinado, o indivíduo emerge como objeto do saber e da prática médica.

Para arrematar essas colocações, ressalto que o hospital hoje passa a ser também um espaço de organização burocrática, onde há um princípio hierárquico que, conforme Weber, apud Teixeira (1991: 73), divide os participantes de uma organização em três camadas: "os governantes que estabelecem as regras; os administradores, que as interpretam e aplicam; e os súditos ou subordinados, que apenas as cumprem".

O hospital ainda pode ser considerado uma instituição panóptica que, segundo Foucault (1993: 178), é;

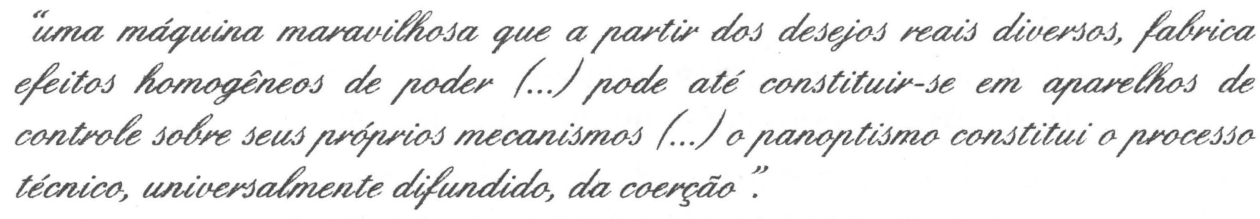

Após essas considerações fica mais claro conhecer a complexa estrutura hospitalar que a "borboleta" visitou.

Ficou evidente na história a disciplinarização hospitalar, o poder do médico, a burocracia para marcar uma consulta, o registro da ocorrência do fato no ProntoSocorro, o ritual da visita médica. As normas e rotinas são o guia disciplinador e norteador do trabalho, possibilitando uma relação de poder dos profissionais ao mesmo tempo de subordinação. É nesse "falso" poder que se insere a alienação e o adestramento conduzindo a uma falta de liberdade do homem, enquanto sujeito em seu processo de trabalho.

Podemos perceber na história que o hospital procura ser um local de "resolução de problemas" das pessoas doentes que conseguem ter acesso ao mesmo.

A filosofia e objetivo do hospital, quando estão explícitos, não são levados em consideração quando se toma decisões, prevalecendo sempre propostas para diminuir os custos e não permitindo um atendimento adequado ao usuário e colocando, muitas vezes, a vida dos profissionais em risco pela falta de condições adequadas para o exercicio do trabalho.

A hierarquia da estrutura hospitalar pode ser detectada nos seguintes personagens: diretor-geral, nas direções de enfermagem, clínica, administrativa, de ensino e pesquisa, médico, enfermeira-chefe, técnica e auxiliar de enfermagem. Essa suposição da existência da estruturação funcional pode não passar de um mero instrumento manipulador das instâncias de poder. 
Outra característica que está presente é o hospital como sendo não somente um lugar de cura, mas também de registro, acúmulo e produtor de saber, onde 0 médico compartilha com seus alunos o conhecimento da "fratura interessante".

Podemos verificar que o hospital é um local em que se exerce a relação de poder e que funciona como rede e não como propriedade específica de alguém. Os micropoderes existem integrados ou não com o Estado. Na história, a relação que se estabelece com o Estado são as Políticas de Saúde, manifestadas no serviço de marcação pelo não atendimento de Dona Maria, mesmo pagando altos impostos ao Estado. Outro exemplo é a decisão sobre a redução de custos e outro é a falta de estrutura e condições adequadas para o trabalho, não importando quem será prejudicado com isso, demonstrando realmente a escassez de verbas destinadas ao setor saúde, mesmo com o aumento da demanda.

Os baixos salários expressados pela auxiliar e a técnica de enfermagem são decorrentes das Políticas de Saúde, não no aspecto filosófico-conceitual, mas no aspecto político em si, no que diz respeito à valorização do profissional de saúde.

$\mathrm{Na}$ história perpassa ainda a disciplininarização do espaço hospitalar em: setor de Marcação de Consultas, Pronto-Socorro, Unidade de Internação e Ala Administrativa.

\section{MICROPODER DA INFORMAÇÃO}

A história focaliza esse micropoder do controle efetivo pelo médico das informações referentes ao paciente, que está presente no momento do ProntoSocorro onde a mãe insistentemente pedia informações sobre o seu filho e a enfermeira não fornecia nenhuma informação, pois quem poderia fazê-lo era o médico que não estava no momento. Outra passagem que podemos observar é na unidade de internação quando o médico detém o saber e todo o saber assegura $\circ$ exercício do poder, quando o paciente insistentemente solicita informações sobre o seu estado de saúde e não obtém uma resposta consistente para a sua dúvida.

Isso vem reforçar o que Boltanski descreve sobre a relação doente-médico e a comunicação (1984: 42) de que:

\footnotetext{
a doente (...) reprovou essencialinente ao médico é "ñas ser franco", "não dizer diveito a que a gente tem "não mostrar "udo o que está pensando" $e$ o mutismo do médico só pode reforgar a ansiedade dos mesmos /... I face à doença e sua desconfiança desse juiz cujo veredicto se ignora.
}

O poder hegemônico do médico no setor saúde é um forte mecanismo de subordinar os outros profissionais dentro dos seus serviços como está também demonstrado na história. Sobre essa hegemonia médica , Pires (1989: 45) se manifesta: 
é fenomeno resultante do processo de apropriação pelos médicos do saber de sacide dos povos, transformando-a em saber médico. Foi construida num processo de mültipla determinação, que envolvem a velasãa organica dos médicos ass interesses das classes dominantes, nos diversos momentos históricos, a de profissionalização dos demais exercentes das açöes de saude, sobre a formagão e a emissão das normas disciplinadoras do exercicio profissional e pela apropriagcão dos cargos administrativos gevenciais das instituigöes de saude a servigo dos interesses econômicos hegemônicos e da manutenção do "status qua", bem como pela intervenção, enquanto categoria, no próprio aparelho de Éstado.

Outra forma de exercer a dominação do saber é na prescrição médica que apresenta um caráter decisório e definitivo e onde a equipe de enfermagem a executa. As ordens expressas do médico neurologista quanto ao número de consulta para não se atrasar em seu consultório particular.

Essa é uma questão que deve ser avaliada, pois, muitas vezes, os médicos são contratados para 40 horas semanais e atuam 2 horas por dia. Isso é um desrespeito ao usuário e também aos profissionais que trabalham na instituição.

O que perpassa pela história é o uso e o abuso da informação e da comunicação com as pessoas. Tanto o médico quanto a enfermeira deveriam ter prestado as informações às pessoas, evitando que as mesmas ficassem angustiadas, desesperadas, agravando de certa forma a situação. Cabe ressaltar que o direito às informações está assegurado no Código de Defesa do Consumidor.

As informações imprecisas prestadas à Maria no setor de marcação de consultas é uma desconsideração pelo ser humano, é uma forma de "violência" que precisamos rever.

Gostaria de ressaltar que é importante que todos os profissionais que atuam dentro do setor de saúde percebam e façam um reflexão de como usam o micropoder da informação-comunicação e que encontrem formas mais amenas de fazer uso delas proporcionando que muitas situações desagradáveis possam ser evitadas.

\section{MICROPODER SOBRE O CORPO}

Para iniciar o comentário desse micropoder, trago as palavras de Foucault (1993: 127):

a corpo humano entra numa maquinaria de poder que a esquadrinha, o desarticula e recompóe. Ulma ánatomia politica' que é também igualmente uma "mecanica do poder," ela define como se pode ter dominio 
sobre o corpo dos outros, não simplesmente para que fasam a que se quer, mas para que operem como se quer, com as técnicas, segundo a rapidez e a eficacia que se determina. A disciplina fabrica assim corpos submissos e exercitados, corpos "lóceis".

Essa colocação do autor é expressa enfaticamente de duas formas na história: a dominação do corpo do paciente/familiar e dominação do corpo dos funcionários.

Em relação à dominação do corpo do paciente/familiar podemos lembrar, no setor de Marcação de Consultas, a desconsideração por parte do funcionário com o ser humano, considerando o seu corpo como um objeto, uma bola de "pingue-pongue" que se joga com a maior facilidade.

No Pronto-Socorro, o menino é considerado como uma "fratura interessante", onde passa a ser para o médico/professor e seus alunos um objeto de observação e manipulação que deve ser bem visto e gravado na memória. Ninguém se preocupou com a identificação do menino bem como sua ansiedade em ter a mãe presente com ele. A enfermeira teve um poder de mando sobre o corpo da mãe, ao mantê-la afastada do filho, para garantir a norma, e esquecendo que, muitas vezes, o melhor remédio é aquele que não fica em ampola ou comprimido.

Podemos ainda verificar a "posse" do médico sobre o corpo do menino, como único dono e detentor do saber, não respeitando a autonomia de outros profissionais.

Acredito que todos os profissionais devem ter responsabilidade com 0 usuário, cada um dentro de sua especificidade/autoridade, mas não podemos confundir isso com possessividade e autoritarismo sobre o mesmo. $\mathrm{O}$ que muitas vezes falta é o trabalho em equipe e o respeito mútuo.

$\mathrm{Na}$ Unidade de Internação detectamos o uso de número dos leitos para identificar as pessoas, e exteriorizado pelo paciente ao médico, quando refere perda de sua identidade. O corpo novamente corresponde a alguma forma de manipulação, a posse do médico sobre o paciente como sua propriedade, a execução de técnicas (banho, RX, curativos, medicação, etc.), a desconsideração com a dúvida do paciente, e os profissionais manejando com técnicas de "enrolação", bem como o paciente sendo sujeitado a tudo por estar num ambiente hospitalar. Essa manipulação do corpo vem reforçar o que Foucault (1993: 164) descreve: "o exame é um controle normalizante, uma vigilância que permite qualificar, classificar e punir".

Em relação à dominação do corpo dos funcionários, podemos destacar: as normas e rotinas que os funcionários devem cumprir para garantir a normalização dos serviços, bem como para manter a relação de poder de subordinar e ser subordinado. 
A falta de material adequado para o trabalho colocando muitas vezes em risco sua própria vida, também é uma forma de dominação do corpo.

A hierarquia é uma forma de vigilância, na medida em que é ao mesmo tempo uma peça interna no aparelho de produção e uma engrenagem especifica da disciplina. (Diretor-Geral, Diretores, Médicos, Enfermeira-Chefe, Técnico e Auxiliar de enfermagem...)

Podemos sintetizar dizendo que os profissionais são treinados para saber manejar, controlar as situações do seu espaço de trabalho e que a instituição espera deles eficiência. Suas funções são disciplinadoras, isto é um modo de exercer o poder utilizando-se de um conjunto de instrumentos, de técnicas, de procedimentos, etc. como um dos meios de caracterizar a instituição.

Outra situação que chama a atenção é a postura do enfermeiro em relação ao horário de visita. Para cumprir as normas e rotinas, coloca o seu poder em jogo e ameaça com o uso da força caso os horários não sejam rigorosamente cumpridos.

Está na hora da instituição e seus profissionais reverem a questão do horário de visitas não como uma forma de "favor" que o hospital presta, como um direito que as pessoas possuem de estar perto de seus familiares e amigos.

O espaço que o auxiliar e técnico de enfermagem não possuem para falar de suas ansiedades indica que ai também o enfermeiro cumpre o papel de controlar e vigiar cortando as pausas para troca de idéias, incentivando o silêncio, porque "há muito para se fazer".

Nesses três micropoderes que ora apresentei procurei destacar os pontos principais, enfocados na história e acredito que haja muito mais. Em cada micropoder analisado percebo que existem outros e, como diz Foucault, que os poderes funcionam como uma rede de dispositivos ou mecanismos que circulam no poder do Estado e na estrutura social.

\section{UMA PALAVRA FINAL}

Gostaria de colocar algumas palavras finais para que possam servir de reflexão a todas as pessoas que ficaram inquietas com a história e que acreditam que podemos, a partir da consciência e do compromisso, modificar o local onde trabalhamos.

O poder faz parte e é necessário para a sobrevivência dos homens. Mas como construir uma outra história onde a relação de poder não seja exercida de forma tão desumana?

Talvez uma das saídas seja pela discussão ética. Do ponto de vista ético, somos pessoas e não podemos ser tratados como objetos. Os valores éticos são a expressão e a garantia de nossa condição de sujeitos, proibindo moralmente que nos transformem em coisa usada e manipulada por outros. A ética permite 
sermos conscientes de nós e dos outros, sermos dotados de vontade, sermos responsáveis e livres.

Por essa via valores humanos devem ser resgatados, tais como: o respeito à identidade, o direito à informação, a prática do consentimento informado, a flexibilidade das normas e rotinas, o resgate do trabalho em equipe para benefício do cliente e não desse ou daquele profissional, o acesso real ao atendimento, a intercomunicação em que os atores sejam cidadãos...

E você, como poderá construir outra história sobre as relações de micropoderes no processo de trabalho dentro da estrutura hospitalar para que a borboleta possa conhecê-la de forma que não fique espantada, triste, indignada e sufocada?

ABSTRACT: Through history, this paper makes an attempt to show the micropower relationships which take place in a hospital during the work of some professionals when they are performing their assignments. Foucaut's studies and other authors, who exploited his works, are the theoretical basis to support this history interpretation. The searched micropowers are the following: the micropower over the hospital structure, information and the human body.

KEYWORDS: Power - Micropower - Hospital structure - Ethics.

\section{REFERÊNCIAS BIBLIOGRÁFICAS}

1. BOLTANSKI, Luc. As classes sociais e o corpo. 3 ed. Rio de Janeiro: Graal, 1989.

2. DELEUZE, Gilles. Foucault. São Paulo: Brasiliense, 1.988.

3. FOUCAULT, Michel. Microfísica do poder. 11 ed. Rio de Janeiro: Graal, 1993.

4. Vigiar e punir. 10 ed. Petrópolis: Vozes, 1993.

5. LUNARDI, V. L. Fios visíveis/invisíveis no processo educativo de (des) construção do sujeito enfermeira. Porto Alegre: 1994. (Dissertação de Mestrado).

6. MACHADO, R. Por uma genealogia do poder. In: Microfísica do poder. 11 ed. Rio de Janeiro: Graal, 1993. 
7. MOREY. Michel Foucault. Un diálogo sobre el poder y otras conversaciones. Buenos Aires: Alianza, 1990.

8. PIRES, Denise. Hegemonia médica na saúde e a enfermagem. São Paulo: Cortez, 1989.

9. TEIXEIRA, H. A. A. Dar ul maraftan, morada dos que precisam ser acorrentados. Florianópolis, 1991 (Dissertação de Mestrado) 